\title{
Author Index of Volume 6
}

Barberis, Julio Alberto, 31

Bennett, Graham, 165

Brigman, James, 69

Castrilli, J. F., 9

Cubbage, Frederick W., 125

Dines, A. J., 9

Dobbert, Jean-Pierre, 110

Ellefson, Paul V., 125
Hansmeyer, K. H., 23

Kimball, Lee, 69, 117

Kohlegger, Karl, 25

Kromarek, Pascale, 91

Malanczuk, Peter, 35, 97, 182

Navid, Daniel, 17
Odidi, Okiki, 18

Oedekoven, Karl, 180

Ofosu-Amaah, Waafas, 173

Rest, Alfred, 82

Schneider, Adolf R. H., 69, 117, 156

Soell, Hermann, 28

Willheim, Ernst, 79 